\title{
Interaction between alcohol dehydrogenase II gene, alcohol consumption, and risk for breast cancer
}

\author{
T Stürmer*,, ,2, S Wang-Gohrke ${ }^{3}$, V Arndt ${ }^{1,2}$, H Boeing ${ }^{4}$, X Kong ${ }^{3}$, R Kreienberg ${ }^{3}$ and H Brenner ${ }^{1,2}$ \\ 'Department of Epidemiology, German Centre for Research on Ageing, Bergheimer Str. 20, 69115 Heidelberg, Germany; ${ }^{2}$ Department of Epidemiology, \\ University of Ulm, Helmholtzstr. 22, 8908 I Ulm, Germany; ${ }^{3}$ Department of Obstetrics and Gynecology, University of Ulm, Frauensteige I4, 89075 Ulm, \\ Germany; ${ }^{4}$ German Institute for Nutritional Research, Arthur-Scheunert-Allee 1/4-I 16, 14558 Bergholz-Rehbrücke, Germany
}

Maelll Restriction Fragment Length Polymorphism in exon 3 of the alcohol dehydrogenase II was assessed in serum from 467 randomly selected German women and 278 women with invasive breast cancer to evaluate the interaction between a polymorphism of the alcohol dehydrogenase II gene, alcohol consumption and risk for breast cancer. In both groups, usual consumption of different alcoholic beverages was asked for using semiquantitative food frequency questionnaires. We used multivariable logistic regression to separately estimate the association between alcohol consumption and alcohol dehydrogenase II polymorphism in the population sample and women with breast cancer. The alcohol dehydrogenase II polymorphism was detected in 14 women from the population sample (3.0\%) and in 27 women with invasive breast cancer (9.7\%). Frequency of alcohol consumption was independent of the genotype in the population sample. In women with breast cancer, there was a significant inverse association between the alcohol dehydrogenase II polymorphism and frequency of alcohol consumption (adjusted case-only odds ratio over increasing frequency of alcohol consumption $=0.5$; $P$ for interaction=0.02). We observed a gene-environment interaction between the alcohol dehydrogenase II polymorphism, alcohol consumption, and risk for breast cancer. Breast cancer risk associated with alcohol consumption may vary according to the alcohol dehydrogenase II polymorphism, probably due to differences in alcohol metabolism.

British Journal of Cancer (2002) 87, 519-523. doi:10.1038/sj.bjc.6600500 www.bjcancer.com

(c) 2002 Cancer Research UK

Keywords: alcohol dehydrogenase II gene (ADH2); alcohol consumption; gene-environment interaction; breast cancer; epidemiology

Alcohol might very well be one of the few modifiable risk factors for breast cancer (Longnecker, 1994; Smith-Warner et al, 1998; Singletary and Gapstur, 2001; Willett, 2001). Despite growing interest in genetic polymorphisms of the enzymes involved in alcohol metabolism for several diseases associated with alcohol comsumption (Hines et al, 2001; McCarver, 2001; Yamauchi et al, 2001a,b), data regarding the role of these polymorphisms as to the risk for breast cancer are sparse (Freudenheim et al, 1999; Hines et al, 2000). These polymorphisms are good candidates for gene-environment interactions (Millikan et al, 1995), however, because they are likely to influence the most plausible biologic mechanism linking alcohol consumption to risk for breast cancer, i.e. endogenous oestrogens.

In humans, alcohol is almost entirely metabolised by oxidative detoxification, mainly dependent on two enzymes, class I alcohol dehydrogenase $(\mathrm{ADH})$ and acetaldehyde dehydrogenase (ALDH). Both enzymes exhibit genetic polymorphisms influencing the rate of conversion from alcohol to acetaldehyde and to acetate (Smith, 1986). The class I ADH isoenzymes are formed by dimeric associations of $\alpha, \beta$, and $\gamma$ subunits controlled by three separate gene loci $\mathrm{ADH} 1, \mathrm{ADH} 2$, and $\mathrm{ADH} 3$, respectively (Agarwal and Goedde, 1990). Despite recent reports regarding the ADH3 polymorphism and risk for breast cancer (Freudenheim et al, 1999; Hines et al, 2000), nothing is known about the role of the less frequent but

*Correspondence: T Stürmer; E-mail: sturmer@dzfa.uni-heidelberg.de Received I0 May 2002; revised 12 June 2002; accepted I4 June 2002 metabolically more relevant $\mathrm{ADH} 2$ polymorphism and its interaction with alcohol consumption for the risk of breast cancer.

The aim of the study was to test the a priori hypothesis of an interaction between the ADH2-2 polymorphism alone, alcohol consumption, and the risk for breast cancer in Caucasian women.

\section{MATERIALS AND METHODS}

We used the case-only design (Khoury and Flanders, 1996) to evaluate the interaction between the $\mathrm{ADH} 2-2$ polymorphism and alcohol consumption with respect to the risk for breast cancer. The case-only design has more power to assess gene-risk factor interactions than the case-control design, but its applicability depends on the independence of the genetic factor and the risk factor in the population. Therefore, the independence between the $\mathrm{ADH} 2$ polymorphism and frequency of alcohol consumption was first assessed in a random sample of the German population.

\section{Random population sample}

The population sample consisted of women selected from a national health and nutrition survey conducted among healthy people in the western part of Germany in 1987/1988. The survey methodology has been previously described in detail (Schneider et al, 1992; Speitling et al, 1992). In brief, a stratified probability sample was drawn from the noninstitutionalised adult population $(\geqslant 18$ years of age) of German nationality. With an overall participation rate of about $70 \%, 1132$ women were recruited in the study. Personal interviews were conducted at the participants' homes and 
included detailed information on medical history, dietary habits including alcohol consumption, and various life-style characteristics. Blood samples were obtained by venipuncture after fasting overnight from 965 women $(85 \%)$. Sera were stored in the gas phase of liquid nitrogen at $-130^{\circ} \mathrm{C}$.

\section{Women with breast cancer}

Women with breast cancer were recruited in the context of a statewide study on risk factors and diagnostic procedures for various forms of cancer, including breast cancer, conducted in Saarland, a state with about one million inhabitants in Western Germany. The study was approved by local and regional institutional review boards. Patients 80 years of age or younger, with a first diagnosis of invasive breast cancer between 1 October 1996 and 28 February 1998 were eligible and recruited for the study by their treating physicians during the first hospitalisation due to the cancer, typically several days to weeks after initial treatment (Arndt et al, 2002). Out of 458 patients deemed suitable for participation by their treating physicians, $387(85 \%)$ fulfilled all of the inclusion criteria stated above and were willing to participate. After written informed consent, interviews following a standardised questionnaire and blood drawings were performed by trained medical doctors. The interview included detailed information on known risk factors for breast cancer, including alcohol consumption during the year preceding the onset of symptoms. Clinical and pathological characteristics of the breast cancers, including menopausal status, were abstracted from hospital records, including pathology reports. Blood samples were obtained from 288 women with breast cancer $(74.4 \%$, the remaining women did not consent to blood drawing or blood drawing was not possible) and were immediately transported to the study centre and centrifuged on the same day. Sera were stored at $-80^{\circ} \mathrm{C}$. For the present analysis, eight women with non-German nationality and two in whom genotyping failed were excluded.

\section{Genotyping}

Serum samples from the population sample and women with breast cancer were analysed separately and without further information regarding the women (including their alcohol consumption) according to the same protocol in a central laboratory at the Department of Obstetrics and Gynecology of the University of Ulm. The analysis of MaeIII RFLP was based on the PCR amplification of a fragment using the following primers: sense primer, 5'-AAT CTT TTC TGA ATC TGA ACA G-3', and anti-sense primer 5'-GAA GGG GGG TCA CCA GGT TG-3'. All PCRs were carried out in $25 \mu \mathrm{l}$ aliquots containing $5 \mu \mathrm{l}$ of denaturated serum, $5 \mathrm{pmol}$ of each primer, $1 \mathrm{X}$ reaction buffer, $50 \mu \mathrm{M}$ dNTPs, and $0.25 \mathrm{U}$ Taq polymerase. The amplification was for 30 cycles each consisting of $1 \mathrm{~min}$ denaturing at $94^{\circ} \mathrm{C}, 1 \mathrm{~min}$ of annealing at $60^{\circ} \mathrm{C}$ and $1 \mathrm{~min}$ of extension at $72^{\circ} \mathrm{C}$. An initial denaturation step of $3 \mathrm{~min}$ at $94^{\circ} \mathrm{C}$ and a final extension at $72^{\circ} \mathrm{C}$ for 5 min were used. PCR products were digested to completion with MaeIII at $55^{\circ} \mathrm{C}$ for $12 \mathrm{~h}$. Digests were separated on a $12 \%$ polyacrylamide gel. All ethidium bromide-stained fragments were analysed on a UV source using an image analysis system. The $\mathrm{ADH}$-2 allele of the polymorphism was defined as the presence of the MaeIII digestive site, according to a previous publication (Goedde et al, 1992).

\section{Alcohol consumption}

In both the population sample and women with breast cancer, consumption of different alcoholic beverages was assessed using a semiquantitative food-frequency questionnaire. Women from the population sample were asked about the usual number of days per week on which they consumed different beverages as well as the usual quantity of these beverages consumed per week (Müller et al, 2001). Women with breast cancer were asked about the usual consumption of defined quantities of different alcoholic beverages (beer, wine, spirits) per day, week, or month in the year preceeding the onset of symptoms. In all women, the usual frequency of consumption of alcoholic beverages was categorised into less than once a week, once a week, and more than once a week according to the alcoholic beverage most often consumed.

\section{Statistical analysis}

Out of the random population sample, we randomly selected up to two women within the same 5-year age-category for every woman with breast cancer. We then described sociodemographic factors and known or suspected risk factors for breast cancer in this age-matched population sample and women with breast cancer. The odds ratios (OR) and their 95\% confidence intervals (CI) for the association between categories of alcohol consumption and the $\mathrm{ADH} 2$ polymorphism were estimated separately in the population sample and women with breast cancer using multivariable logistic regression. All analyses were controlled for age (continuous), body mass index (weight in $\mathrm{kg}^{2}$ height in $\mathrm{m}$, continuous), smoking (never, ever), age at menarche (continuous), parity $(0,1,2,3$ or more), and history of breast cancer in the mother. The case-only analyses were additionally controlled for menopausal status, age at menopause (continuous), and cumulative years of hormone replacement therapy (continuous) (Colditz and Rosner, 2000).

\section{RESULTS}

The mean age of the population sample of 467 women was 54.9 years, slightly lower than the mean age of the 278 cases with invasive breast cancer (57.2 years, see Table 1 ). The majority of women with breast cancer $(72.7 \%)$ were postmenopausal at the time of diagnosis. Whereas the body mass index was slightly lower in the population sample than in women with breast cancer, the prevalence of cigarette smoking (current and former) was virtually identical $(41.5 \%)$. In the population sample, the mean age at menarche was 13.8 years compared to 13.5 years in women with breast cancer. About one-third of all women had given birth to two, and another third to three or more children. A family history of breast cancer in the mother was reported by 18 women from the population sample $(3.9 \%)$ and 24 women with breast cancer (8.6\%).

The majority of women with breast cancer were postmenopausal $(72.7 \%)$ and had T1 $(43.8 \%)$ or T2 $(45.2 \%)$ tumours. Most cancers were ductal $(74.1 \%)$ and oestrogen $(70.1 \%)$ as well as progesteron

Table I Description of random sample of German women and women with invasive breast cancer

\begin{tabular}{|c|c|c|}
\hline & Population sample & Breast cancer \\
\hline $\mathrm{N}$ & 467 & 278 \\
\hline Age (years), mean (s.d.) & $54.9(10.9)$ & $57.2(11.5)$ \\
\hline BMI $\left(\mathrm{kg} \mathrm{m}^{-2}\right)$, mean (s.d.) & $26.0(4.5)$ & $26.5(4.9)$ \\
\hline Cigarette smoking (ever), N (\%) & $194(41.5)$ & $114(41.5)$ \\
\hline Age at menarche (years), mean (s.d.) & $13.8(1.7)$ & $13.5(1.7)$ \\
\hline \multicolumn{3}{|l|}{ Parity, N (\%) } \\
\hline No child & $79(17.0)$ & $41(14.9)$ \\
\hline a child & $85(18.2)$ & $60(21.7)$ \\
\hline 2 children & $147(31.6)$ & $84(30.4)$ \\
\hline 3 or more children & $155(33.3)$ & $91(33.0)$ \\
\hline $\begin{array}{l}\text { Family history of breast cancer } \\
\text { (mother only), } N(\%)\end{array}$ & $18(3.9)$ & $24(8.6)$ \\
\hline
\end{tabular}


(65.1\%) receptor positive, and $42.1 \%$ had already metastasised to lymph nodes at the time of diagnosis (data not shown).

In the population sample, 14 heterozygotes of $\mathrm{ADH} 2(\beta 1 \beta 2)$ were detected $(3.0 \%)$ compared to 27 heterozygotes in women with breast cancer $(9.7 \%$, see Table 2$)$. None of the women was $\beta 2 \beta 2$ homozygote.

The proportion of women consuming alcoholic beverages less often than once a week or more often than once a week was approximately equal (around $40 \%$ each) in women from the population sample (see Table 2). The prevalence of the ADH2 polymorphism by category of alcohol consumption ranged from $2.1-3.3 \%$ and was independent of the frequency of alcohol consumption (adjusted OR for trend with increasing frequency of alcohol consumption $=0.9, P=0.9$ ).

Since the frequency of alcohol consumption was independent of the $\mathrm{ADH} 2$ polymorphism in the population sample, the possible interaction between the $\mathrm{ADH} 2$ polymorphism and frequency of alcohol consumption as to the risk for breast cancer could be assessed using the case-only design. During the last year preceeding the onset of symptoms, 117 women with breast cancer consumed alcoholic beverages less often than once a week and 98 women reported consumption of alcoholic beverages more often than once a week. The prevalence of the $\mathrm{ADH} 2$ polymorphism monotonically decreased with increasing frequency of alcohol consumption from $15.4 \%$ in women consuming alcoholic beverages less often than once a week to $4.1 \%$ in women consuming alcoholic beverages more often than once a week. The case-only analysis confirmed the inverse interaction between the $\mathrm{ADH} 2$ polymorphism and frequency of alcohol consumption with respect to risk for breast cancer. The adjusted case-only OR for once a week consumption of alcoholic beverages compared to women consuming alcoholic beverages less often was 0.5 (95\% CI: $0.2-1.7$ ). In women consuming alcoholic beverages more often than once a week, this OR was even more pronounced $(\mathrm{OR}=0.3 ; 95 \% \mathrm{CI}: 0.1-0.9)$. There was a statistically significant trend for a lower prevalence of the $\mathrm{ADH} 2$ polymorphism with increasing frequency of alcohol consumption $(P=0.02)$.

Additional case-only analyses revealed that the observed interaction was independent of menopausal status and any of the known risk factors for breast cancer presented in Table 1, essentially unchanged using usual amount $\left(\mathrm{g} \mathrm{day}^{-1}\right)$ of alcohol consumed instead of frequency of consumption, and even more pronounced
(OR over increasing frequency of alcohol consumption $=0.4 ; 95 \%$ CI: $0.2-0.9)$ in women with oestrogen receptor positive tumours (data not shown).

\section{DISCUSSION}

In a population based case-only study of women with breast cancer we observed a previously unknown interaction between frequency of alcohol consumption, the $\mathrm{ADH} 2$ polymorphism, and risk for breast cancer.

The use of the case-only study design is dependent on the assumption that the frequency of alcohol consumption does not vary according to the genotype in the population. Since we, like others (Gilder et al, 1993; Whitfield et al, 1998; Borras et al, 2000), observed no association between ADH2 polymorphism and alcohol consumption in women without breast cancer, we could assess the interaction between these factors and risk for breast cancer using the case-only analysis, which is more powerful to detect gene-environment interactions than a case-control study (Piegorsch et al, 1994). In contrast to a case-control analysis, our analytic strategy has also the advantage of assessing associations independently in women with identical data collection procedures (i.e. first within women from the population sample and then within women with breast cancer) and therefore avoiding problems of differential misclassification often encountered in case-control studies. Furthermore, the case-only design allowed to control for menopausal status, age at menopause, and cumulative years of hormone replacement therapy in the multivariable analysis as recently suggested (Colditz and Rosner, 2000).

$\mathrm{ADH} 2$ is known as a key enzyme in the first step of detoxification of alcohol to acetaldehyde. The ADH2-2 allele, which encodes the more active $\beta 2$-subunit, is more prevalent in Asian populations $(60-80 \%)$ than Caucasians $(0-10 \%)$ (Goedde et al, 1992) and leads to an increased metabolic rate in vitro $\left(9.2 \mathrm{~min}^{-1}\right.$ for $\beta 1 \beta 1$ and $400 \mathrm{~min}^{-1}$ for $\beta 2 \beta 2$ isoenzymes) (Bosron and Li, 1986). Furthermore, the ADH2 polymorphism has been shown to increase the alcohol elimination rate after alcohol consumption (Thomasson et al, 1993) and to influence the metabolism of alcohol in peripheral tissues (Takeshita et al, 1996).

Blood alcohol levels have been associated with oestradiol levels, which play a major role in the development of breast cancer (The Endogenous Hormones and Breast Cancer Collaborative Group,

Table 2 ADH2 polymorphism according to frequency of alcohol consumption in the population sample and in women with invasive breast cancer

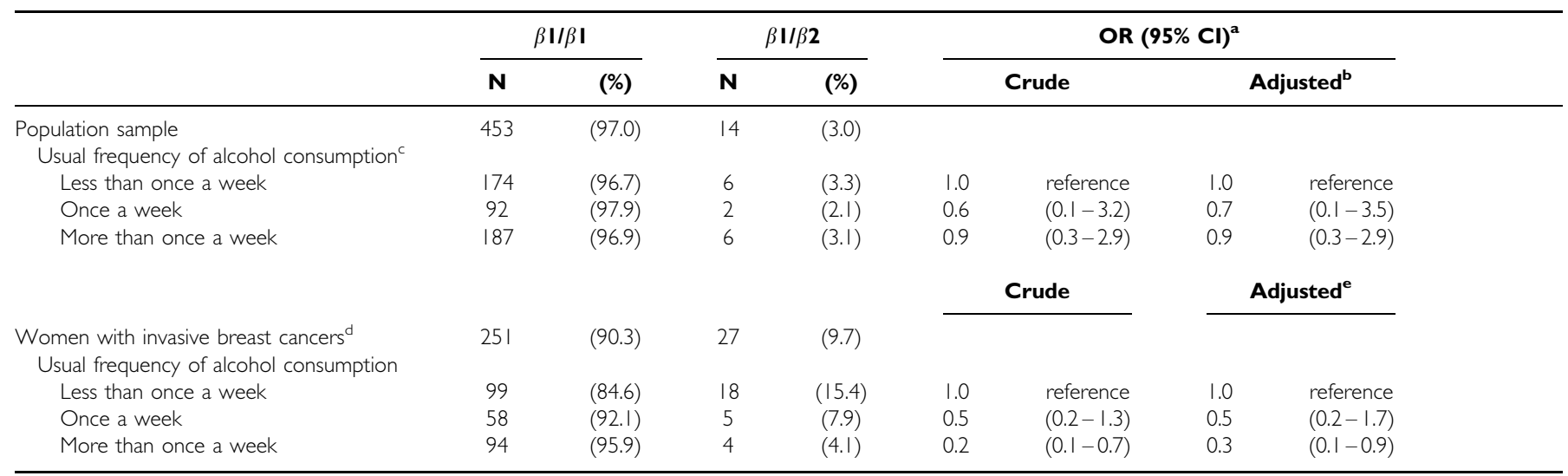

${ }^{a}$ Odds ratio and $95 \%$ confidence interval from logistic regression; analysis in women with invasive breast cancer corresponds to case-only analysis of interaction between $\mathrm{ADH} 2$ polymorphism and frequency of alcohol consumption with respect to risk for breast cancer; ${ }^{b}$ For age, body mass index (weight in kg/squared height in $\mathrm{m}$ ), frequency of alcohol consumption, smoking, age at menarche, and parity; ' Odds ratio for trend with increasing category of frequency of alcohol consumption (adjusted model) $=0.9$ ( $95 \%$ Cl: $0.5-1.7$ ); $P_{\text {trend }}=0.9 ;{ }^{d}$ Odds ratio for trend with increasing category of frequency of alcohol consumption (adjusted model) $=0.5$ ( $95 \% \mathrm{Cl}$ : $0.3-0.9$ ); $P$ trend $=0.02 ;{ }^{e}$ Case-only odds ratio adjusted for age, body mass index (weight in kg/squared height in $\mathrm{m}$ ), frequency of alcohol consumption, smoking, age at menarche, parity, menopausal status, age at menopause, years of hormone replacement therapy, and history of breast cancer in the mother. 
2002). Although the association between alcohol consumption or blood alcohol levels and oestradiol levels in pre- (Reichman et al, 1993) and postmenopausal (Ginsburg et al, 1996, Ginsburg, 1999) women is not completely understood, the increased alcohol elimination rate in individuals with the polymorphism may lead to lower oestradiol levels and might therefore be an explanation for the observed inverse interaction. Faster clearance of alcohol might furthermore mitigate the depression of androgens and sex hormone binding globulin associated with alcohol intake (Madigan et al, 1998; Hines et al, 2000), the latter again leading to a decreased bioavailability of oestrogens.

The difference in prevalence of the $\mathrm{ADH} 2$ polymorphism in the population sample and in women with breast cancer is intruiging. Is the $\mathrm{ADH} 2$ polymorphism a previously unknown risk factor for breast cancer? This difference needs to be interpreted with caution. Women from the population sample were recruited nationwide and approximately 10 years before the recruitment of women with breast cancer. The population sample has been found to be representative of the German population (Schneider et al, 1992), however. We furthermore found no regional differences in the prevalence of the ADH2 polymorphism in the population sample $(P=0.4$, data not shown $)$ and changes in the prevalence of the polymorphism over such a short time period are unrealistic. Population stratification or confounding by different genotypes, which are culturally linked to alcohol consumption, is unlikely to introduce relevant bias in this exclusively German population with very similar genetic background (Wacholder et al, 2000). Finally, although the polymorphism was analysed separately in both groups, the same methods were used in the same laboratory by the same technicians.

$\mathrm{ADH}$ has been found in different organs not directly involved in alcohol metabolism, including the breast (Saleem et al, 1984). In combination with xanthine oxidoreductase, $\mathrm{ADH}$ may lead to the formation of reactive oxygen species that themselves have been linked to types of DNA damage typically observed in breast cancer and therefore contribute to breast carcinogenesis (Wright et al,

\section{REFERENCES}

Agarwal DP, Goedde HW (1990) Pharmacogenetics of alcohol dehydrogenase (ADH). Pharmac Ther 45: 69-83

Arndt V, Stürmer T, Stegmaier C, Ziegler H, Dhom G, Brenner H (2002) Patient delay and stage of diagnosis among breast cancer patients in Germany-a population based study. Br J Cancer 86: 1034-1040, doi:10.1038/sj/bjc/660020918

Borras E, Coutelle C, Rosell A, Fernandez-Muixi F, Broch M, Crosas B, Hjelmqvist L, Lorenzo A, Gutierrez C, Santos M, Szczepanek M, Heilig M, Quattrocchi P, Farres J, Vidal F, Richart C, Mach T, Bogdal J, Jornvall H, Seitz HK, Couzigou P, Pares X (2000) Genetic polymorphism of alcohol dehydrogenase in Europeans: the $\mathrm{ADH} 2^{\star} 2$ allele decreases the risk of alcoholism and is associated with $\mathrm{ADH}^{*} 1$. Hepatology 31: $984-989$

Bosron WF, Li TK (1986) Genetic polymorphism of human liver alcohol and aldehyde dehydrogenases, and their relationship to alcohol metabolism and alcoholism. Hepatology 6: $502-510$

Colditz GA, Rosner B (2000) Cumulative risk of breast cancer to age 70 years according to risk factor status: data from the Nurses' Health Study. Am J Epidemiol 152: $950-964$

Duester G (2000) Families of retinoid dehydrogenases regulating vitamin A function: production of visual pigment and retinoic acid. Eur J Biochem 267: $4315-4324$

Freudenheim JL, Ambrosone C, Moysich KB, Vena JE, Graham S, Marshall JR, Muti P, Laughlin R, Nemoto T, Harty LC, Crits GA, Chan AW, Shields PG (1999) Alcohol dehydrogenase 3 genotype modification of the association of alcohol consumption with breast cancer risk. Cancer Causes Control 10: $369-377$

Gilder FJ, Hodgkinson S, Murray RM (1993) ADH and ALDH genotype profiles in Caucasians with alcohol-related problems and controls. Addiction 88: $383-388$
1999). Furthermore, Class I ADH plays an important role in the provitamin A (beta-carotene) metabolism, oxidizing all-trans-retinol and 9-cis-retinol, and might play a role in hydroxysteroid metabolism (Duester, 2000). Therefore, there seems to be evidence that some forms of $\mathrm{ADH}$ may play important roles in human tissues other than the liver, including the breast.

Although we carefully controlled for potential confounding factors in our analysis, the potential for residual confounding by additional factors cannot entirely be ruled out. In particular, the observed risk and interaction may not be entirely due to the $\mathrm{ADH} 2$ polymorphism itself, but also to the linkage of $\mathrm{ADH} 2$ with other genes that are associated with an increased risk for breast cancer. $\mathrm{ADH} 2$ has been observed to be linked to $\mathrm{ADH} 3$ (Borras et al, 2000) and the $\mathrm{ADH} 3^{\star} 1$ genotype was observed to be a risk factor for breast cancer in premenopausal women (Freudenheim et al, 1999). However, given the stronger metabolic effects of $\mathrm{ADH} 2$, the $\mathrm{ADH} 3$ - breast cancer association might also be confounded by $\mathrm{ADH} 2$.

In summary, we observed a previously unknown interaction between alcohol consumption and the ADH2 polymorphism with respect to risk for breast cancer. If replicated, the observed geneenvironment interaction might be a good example for the future need of a concept for tailor-made preventive recommendations taking individual genetic susceptibilities into account. It might, however, also be a good example for the complexity and difficulties in applying such recommendations in practice due to the low prevalence of the $\mathrm{ADH} 2$ polymorphism in the caucasian population.

\section{ACKNOWLEDGEMENTS}

The study was supported by grants from the German Cancer Foundation (M24/95/BRI) and the faculty of medicine of the university of Ulm (P583, P589).
Ginsburg ES, Mello NK, Mendelson JH, Barbieri RL, Teoh SK, Rothman M, Gao X, Sholar JW (1996) Effects of alcohol ingestion on estrogens in postmenopausal women. JAMA 276: $1747-1751$

Ginsburg ES (1999) Estrogen, alcohol and breast cancer risk. J Steroid Biochem and Molec Biol 69: 299-306

Goedde HW, Agarwal DP, Fritze G et al (1992) Distribution of ADH2 and ALDH2 genotypes in different populations. Hum Genet 88: $344-346$

Hines LM, Hankinson SE, Smith-Warner SA (2000) A prospective study of the effect of alcohol consumption and $\mathrm{ADH} 3$ genotype on plasma steroid hormone levels and breast cancer risk. Cancer Epidemiol Biomarkers Prev 9: $1099-1105$

Hines LM, Stampfer MJ, Ma J, Gaziano JM, Ridker PM, Hankinson SE, Sacks F, Rimm EB, Hunter DJ (2001) Genetic variation in alcohol dehydrogenase and the beneficial effect of moderate alcohol consumption on myocardial infarction. N Engl J Med 344: 549-555

Khoury MJ, Flanders WD (1996) Nontraditional epidemiologic approaches in the analysis of gene-environment interaction: case-control studies with no controls!. Am J Epidemiol 144: $207-213$

Longnecker MP (1994) Alcoholic beverage consumption in relation to risk of breast cancer: meta-analysis and review. Cancer Causes Control 5: 73-82

Madigan MP, Troisi R, Potischman N, Dorgan JF, Brinton LA, Hoover RN (1998) Serum hormone levels in relation to reproductive and lifestyle factors in postmenopausal women (United States). Cancer Causes Control 9: $199-207$

McCarver DG (2001) ADH2 and CYP2E1 genetic polymorphisms: risk factors for alcohol-related birth defects. Drug Metab Dispos 29: 562-565

Millikan R, DeVoto E, Newman B, Savitz D (1995) Studying environmental influences and breast cancer risk: suggestions for an integrated populationbased approach. Breast Cancer Res Treat 35: 79-89 
Müller E, Stürmer T, Brenner H (2001) Alcohol Intake and HDL Cholesterol: Comparison of Food Frequency Questionnaire and Diet Record in a General Population Sample. J Epidemiol Biostat 6: 297-303

Piegorsch WW, Weinberg CR, Taylor JA (1994) Non-hierarchical logistic models and case-only designs for assessing susceptibility in populationbased case-control studies. Stat Med 13: $153-162$

Reichman ME, Judd JT, Longcope C, Schatzkin A, Clevidence BA, Nair PP, Campbell WS, Taylor PR (1993) Effects of alcohol consumption on plasma and urinary hormone concentrations in premenopausal women. J Natl Cancer Inst 85: $722-727$

Saleem MM, AlTamer YY, Skursky L, AlHabbal Z (1984) Alcohol dehydrogenase activity in the human tissues. Biochemical Medicine 31: 1-9

Schneider R, Eberhardt W, Heseker H, Moch KJ (1992) Die VERA-Stichprobe im Vergleich mit Mikrozensus, Volkszählung und anderen Nationalen Untersuchungen. In Wissenschaftlicher Fachverlag Dr. Fleck, Kübler W, Anders H - J, Heeschen W, Kohlmeier M (eds) Niederkleen

Singletary KW, Gapstur SM (2001) Alcohol and Breast Cancer. Review of Epidemiologic and Experimental Evidence and Potential Mechanisms. JAMA 286: $2143-2151$

Smith M (1986) Genetics of human alcohol and aldehyde dehydrogenases. In Advances in Human Genetics, Harris H and Hirschhorn K (eds) pp 249290 New York (NY): Plenum Press

Smith-Warner SA, Spiegelman D, Yaun SS, van den Brandt PA, Folsom AR, Goldbohm RA, Graham S, Holmberg L, Howe GR, Marshall JR, Miller AB, Potter JD, Speizer FE, Willett WC, Wolk A, Hunter DJ (1998) Alcohol and breast cancer in women. A pooled analysis of cohort studies. JAMA 279: $535-540$

Speitling A, Hüppe R, Kohlmeier M, Matiaske B, Stelte W, Thefeld W, Wetzel S (1992) Methodological handbook, nutrition survey and risk factors analysis. In Wissenschaftlicher Fachverlag Dr. Fleck, Kübler W, Anders HJ, Heeschen W, Kohlmeier M, (eds) Niederkleen
Takeshita T, Mao XQ, Morimoto K (1996) The contribution of polymorphism in the alcohol dehydrogenase $\beta$ subunit to alcohol sensitivity in a Japanese population. Hum Genet 97: 409-413

The Endogenous Hormones and Breast Cancer Collaborative Group (2002) Endogenous Sex Hormones and Breast Cancer in Postmenopausal Women: Reanalysis of Nine Prospective Studies. J Natl Cancer Inst 94: $606-616$

Thomasson HR, Crabb DW, Edenberg HJ, Li TK (1993) Alcohol and acetaldehyde dehydrogenase polymorphisms and alcoholism. Behav Genet 23: $131-136$

Wacholder S, Rothman N, Caporaso N (2000) Population stratification in epidemiologic studies of common genetic variants and cancer: quantification of bias. J Natl Cancer Inst 92: 1151-1158

Whitfield JB, Nightingale BN, Buchholz KK, Madden PAF, Heath AC, Martin MG (1998) ADH genotypes and alcohol use and dependence in Europeans. Alcohol Clin Exp Res 22: $1463-1469$

Willett WC (2001) Diet and breast cancer. J Intern Med 249: 395-411

Wright RM, McManaman JL, Repine JE (1999) Alcohol-induced breast cancer: a proposed mechanism. Free Radical Biol Med 26: 348-354

Yamauchi M, Takamatsu M, Maezawa Y, Takagi M, Araki T, Satoh S, Toda G, Saito S (2001a) Polymorphism of tumor necrosis factor-beta and alcohol dehydrogenase genes and alcoholic brain atrophy in Japanese patients. Alcohol Clin Exp Res 25(Suppl 6): S7-S10

Yamauchi M, Takeda K, Sakamoto K, Searashi Y, Uetake S, Kenichi H, Toda $\mathrm{G}$ (2001b) Association of polymorphism in the alcohol dehydrogenase 2 gene with alcohol-induced testicular atrophy. Alcohol Clin Exp Res 25(Suppl 6): S16-S18 